\title{
Sex, covert prestige and linguistic change in the urban British English of Norwich
}

\author{
PETER TRUDGILL \\ Department of Linguistic Science, University of Reading
}

\section{ABSTRACT}

Women use linguistic forms associated with the prestige standard more frequently than men. One reason for this is that working-class speech has favourable connotations for male speakers. Favourable attitudes to nonstandard speech are not normally expressed, however, and emerge only in inaccurate self-evaluation test responses. Patterns of sex differentiation deviating from the norm indicate that a linguistic change is taking place: standard forms are introduced by middle-class women, non-standard forms by working-class men. (Sociolinguistic variation; linguistic change; women's and men's speech; contextual styles; social class; British English.)

It is known to be the case that in some societies linguistic phenomena are involved in covariation, not only with parameters such as social stratification, social context and age, but also with the parameter of sex. ${ }^{1}$ The fact that the speech of men and women may differ in interesting ways, however, has been noted in only a rather small number of linguistic articles and discussions (see, for example, Haas 1944; Fischer 1958; Sapir 1929), 2 and, until very recently, research on this topic has tended to concentrate either on non-urbanized communities (Haas 1944) or on relatively peripheral aspects of the subject (Hertzler 1954).

In the past few years, however, a number of studies have appeared which have begun to present accurate, structured data illustrating the form that sex differentiation takes in the linguistic communities of complex urbanized societies. For the most part, the work that has been published on this topic is based on sociolinguistic investigations that have been carried out into varieties of urban American English. Shuy, Wolfram \& Riley (1967), Wolfram (1969), and Fasold (1968), for example, have all discussed sex differentiation in the speech of Detroit, while Labov (1966) and Levine \& Crockett (1966) have investigated the same phenomenon in other varieties of American English. This means that, for the first time, we have evidence not only to show that this type of variation actually

[I] I am very grateful to D. Crystal, P. H. Matthews and the editor for the number of helpful comments and suggestions they have made on this paper.

[2] There have also been a number of discussions in general works, cf. Jespersen (1922, chapter 13). See also the summary of other work in Crystal (1971). 
does occur, if only for a restricted number of varieties of one language, but also to illustrate the exact form that this variation takes.

So far, the results of all these studies have one striking feature in common. They are all agreed that women, allowing for other variables such as age, education and social class, consistently produce linguistic forms which more closely approach those of the standard language or have higher prestige than those produced by men, or, alternatively, that they produce forms of this type more frequently. Results of this kind have been obtained only in the study of American English. We are therefore justified in asking: Does the same sort of pattern of differentiation occur in other linguistic communities, including those of Britain, or is it peculiarly a product of the American social structure?

Impressionistically, one would say that sex differentiation of this precise type does occur in British English. It is clearly preferable, however, to be able to demonstrate conclusively that this is actually the case. In this paper I propose to present some data which illustrates quite clearly that this type of differentiation does occur in at least one variety of British English. I shall then attempt to discuss what factors may underlie this form of differentiation, and to consider what role it plays both in the propagation and in the study of linguistic change.

The results from which these figures are taken are based on an urban dialect survey of the city of Norwich carried out in the summer of 1968 with a random sample, 60 in number, of the population of the city, and reported in detail in Trudgill (1971). This sociolinguistic research was concerned mainly with correlating phonetic and phonological variables with social class, age, and stylistic context, and with developing a generative phonological diasystem which would in some way account for all varieties of Norwich English. Some work was also done, however, in studying the relationships that obtain between linguistic phenomena and sex.

In order to relate the phonological material to the social class of informants and the other parameters, a number of phonetic and phonological variables were developed, and index scores calculated for individuals and groups in the manner of Labov (1966). The first of these variables that I wish to discuss is the variable (ng). This is the pronunciation of the suffix -ing in walking, laughing, etc., and is a well-known variable in many types of English. In the case of Norwich English there are two possible pronunciations of this variable: [ $\mathrm{I}]$ ], which also occurs in the prestige accent, $R P$, and [an $\sim$ n]. The former is labelled (ng)-r and the latter (ng)-2.

Index scores were developed for this variable by initially awarding I for each instance of (ng)-1 and 2 for each instance of (ng)-2. These scores were then summed and divided by the total number of instances, to give the mean score. Indices were finally calculated by subtracting $\mathrm{I}$ from the mean score and multiplying the result by 100 . In this case, this gives an index score of 000 for consistent use of RP (ng)-I, and 100 for consistent use of (ng)-2, and the scores are 
equivalent to the simple percentage of non-RP forms used. (For variables with more than two variants this simple relationship, of course, does not apply.) Indices were calculated in the first instance for individual informants in each contextual style and subsequently for each group of informants. The four contextual styles:

\author{
Word List Style: WLS \\ Reading Passage Style: RPS \\ Formal Speech: FS \\ Casual Speech: CS
}

are equivalent to the styles discussed by Labov (1966) and were elicited in a similar manner. Indices for other variables were calculated in the same way.

Table I shows the average (ng) index scores for informants in the five social class groups obtained in the survey, in the four contextual styles. The social class divisions are based on an index that was developed using income, education, dwelling type, location of dwelling, occupation, and occupation of father as parameters. The five classes have been labelled:

Middle Middle Class: MMC
Lower Middle Class: LMC
Upper Working Class: UWC
Middle Working Class: MWC
Lower Working Class: LWC

The table shows very clearly that (ng) is a linguistic variable in Norwich English. Scores range from a high of roo per cent non-RP forms by the LWC in CS to a low of o per cent by the MMC in RPS and by the MMC and LMC in WLS. The pattern of differentiation is also structured in a very clear manner. For each

TABLE I. (ng) Index scores by class and style

\begin{tabular}{lccccr}
\hline \hline & \multicolumn{5}{c}{ Style } \\
\cline { 2 - 6 } Class & WLS & RPS & FS & CS & N: \\
\hline MMC & 000 & 000 & 003 & 028 & 6 \\
LMC & 000 & 010 & 015 & 042 & 8 \\
UWC & 005 & 015 & 074 & 087 & 16 \\
MWC & 023 & 044 & 088 & 095 & 22 \\
LWC & 029 & 066 & 098 & 100 & 8 \\
\hline
\end{tabular}

of the social classes, scores rise consistently from WLS to CS; and for each style scores rise consistently from MMC to LWC.

In his study of this same variable in American English, Fischer (r958) found that males used a higher percentage of non-standard [n] forms than females. 
Since we have now shown that (ng) is a variable in Norwich English, we would expect, if sex differentiation of the type we have been discussing also occurs in British English, that the same sort of pattern would emerge here. Table 2 shows that this is in fact very largely the case. In 17 cases out of 20 , male scores are greater than or equal to corresponding female scores. 3

We can therefore state that a high (ng) index is typical not only of WC speakers in Norwich but also of male speakers. This pattern, moreover, is repeated for the vast majority of the other nineteen variables studied in Norwich. We can therefore claim to have demonstrated that the type of sex differentiation already illustrated in American English also occurs in urban British English: our initial impression is confirmed.

TABLE 2. (ng) Index scores by class, style and sex

\begin{tabular}{llllll}
\hline \hline & & \multicolumn{5}{c}{ Style } \\
\cline { 3 - 6 } \multicolumn{1}{c}{ Class } & Sex & WLS & RPS & FS & CS \\
\hline MMC & M & 000 & 000 & 004 & 031 \\
& F & 000 & 000 & 000 & 000 \\
LMC & M & 000 & 020 & 027 & 017 \\
& F & 000 & 000 & 003 & 067 \\
UWC & M & 000 & 018 & 081 & 095 \\
& F & 011 & 013 & 068 & 077 \\
MWC & M & 024 & 043 & 091 & 097 \\
& F & 020 & 046 & 081 & 088 \\
LWC & M & 060 & 100 & 100 & 100 \\
& F & 017 & 054 & 097 & 100 \\
& & & & & \\
\hline \hline
\end{tabular}

Women informants, then, use forms associated with the prestige standard more frequently than men. How can we explain this phenomenon? What follows is necessarily speculative, but there would appear to be perhaps two interconnected explanatory factors.

r. Women in our society are more status-conscious than men, generally speaking (see Martin 1954), and are therefore more aware of the social significance of linguistic variables. There are two possible reasons for this:

(i) The social position of women in our society is less secure than that of men, and, usually, subordinate to that of men. It may be, therefore, that it is more necessary for women to secure and signal their social status linguistically and in other ways, and they may for this reason be more

[3] The low score obtained by male LMC speakers in CS requires some comment. The score is clearly unrepresentative, being lower than both the RPS and FS scores and the male MMC score, and is due to the fact that only a very small number of instances of this variable happened to be obtained for this group in CS. 
aware of the importance of this type of signal. (This will be particularly true of women who are not working.)

(ii) Men in our society can be rated socially by their occupation, their earning power, and perhaps by their other abilities - in other words by what they do. For the most part, however, this is not possible for women. It may be, therefore, that they have instead to be rated on how they appear. Since they are not rated by their occupation or by their occupational success, other signals of status, including speech, are correspondingly more important.

2. The second, related, factor is that WC speech, like other aspects of WC culture, appears, at least in some Western societies, to have connotations of masculinity (see Labov $1966: 495$ ), probably because it is associated with the roughness and toughness supposedly characteristic of WC life which are, to a certain extent, considered to be desirable masculine attributes. They are not, on the other hand, considered to be desirable feminine characteristics. On the contrary, features such as refinement and sophistication are much preferred.

It has aslo been suggested (Shuy 1969) that this phenomenon may in part be the result of differential responses to the school situation. Female domination would appear to be the norm in primary schools in Britain, and female values (for example the emphasis traditionally placed on quietness in schools) seem to predominate in the teaching situation generally. It is possible that boys react to this kind of domination in a negative way and reject the standard English that is typically taught in schools along with other aspects of the value system to a greater extent than girls.

For the purposes of this paper I want to concentrate on the second factor: the argument that WC speech in our culture has desirable connotations for male speakers. Again, impressionistically speaking, I feel that one would wish to claim that this argument is essentially correct. As it stands at the moment, however, the argument is largely speculative because of the lack of concrete evidence. This lack of evidence has been discussed by Labov (1966b: 108) who states that in New York 'the socio-economic structure confers prestige on the middle-class pattern associated with the more formal styles. [But] one can't avoid the implication that in New York City we must have an equal and opposing prestige for informal, working-class speech - a covert prestige enforcing this speech pattern. We must assume that people in New York City want to talk as they do, yet this fact is not at all obvious in any overt response that you can draw from interview subjects.'

We suspect, in other words, that there are hidden values associated with nonstandard speech, and that, as far as our present argument is concerned, they are particularly important in explaining the sex differentiation of linguistic variables, but so far we have been unable to uncover them or prove that they exist. We can 
guess that these values are there, but they are values which are not usually overtly expressed. They are not values which speakers readily admit to having, and for that reason they are difficult to study. Happily, the urban dialect survey carried out in Norwich has now provided some evidence which argues very strongly in favour of our hypothesis, and which has managed, as it were, to remove the outer layer of overtly expressed values and penetrate to the hidden values beneath. That is, we now have some objective data which actually demonstrates that for male speakers WC non-standard speech is in a very real sense highly valued and prestigious.

Labov has produced evidence to show that almost all speakers in New York City share a common set of linguistic norms, whatever their actual linguistic performance, and that they hear and report themselves as using these prestigious linguistic forms, rather than the forms they actually do use. This 'dishonesty' in reporting what they say is of course not deliberate, but it does suggest that informants, at least so far as their conscious awareness is concerned, are dissatisfied with the way they speak, and would prefer to be able to use more standard forms. This was in fact confirmed by comments New York City informants actually made about their own speech.

Overt comments made by the Norwich informants on their own speech were also of this type. Comments such as 'I talk horrible' were typical. It also began to appear, however, that, as suggested above, there were other, deeper motivations for their actual linguistic behaviour than these overtly expressed notions of their own 'bad speech'. For example, many informants who initially stated that they did not speak properly, and would like to do so, admitted, if pressed, that they perhaps would not really like to, and that they would almost certainly be considered foolish, arrogant or disloyal by their friends and family if they did. This is our first piece of evidence.

Far more important, however, is the evidence that was obtained by means of the Self-Evaluation Test, in which half of the Norwich informants took part. This is particularly the case when the results of this test are compared to those obtained by a similar test conducted by Labov in New York. In the Norwich Self-Evaluation Test, 12 lexical items were read aloud, to informants, with two or more different pronunciations. For example:

$$
\begin{array}{lll}
\text { tune } & \text { I. }[\mathrm{tju}: \mathrm{n}] & \text { 2. }[\mathrm{tz}: \mathrm{n}]
\end{array}
$$

Informants were then asked to indicate, by marking a number on a chart, which of these pronunciations most closely resembled the way in which they normally said this word.

The corresponding Self-Evaluation Test in New York for the variable (r) presence or absence of post-vocalic/ $\mathrm{r}$ ( (a prestige feature) - produced the following results. Informants who in FS used over $3^{\circ}$ per cent $/ r /$ were, very generously, considered to be (post-vocalic) / $r$-users. Seventy per cent of those who, in this 
sense, were $/ r /$-users reported that they normally used $/ r /$. But 62 per cent of those who were not $/ \mathrm{r} /$-users also reported that they normally used $/ \mathrm{r} /$. As Labov says (1966: 455): 'In the conscious report of their own usage... New York respondents are very inaccurate'. The accuracy, moreover, is overwhelmingly in the direction of reporting themselves as using a form which is more statusful than the one they actually use. Labov (1966: 455 ) claims that 'no conscious deceit plays a part in this process' and that 'most of the respondents seemed to perceive their own speech in terms of the norms at which they were aiming rather than the sound actually produced'.

The full results of this test are shown in Table 3 . It shows that 62 per cent of non-/r/-users 'over-reported' themselves as using $/ r /$, and 21 per cent of $/ r /$ users 'under-reported', although in view of Labov's $3^{\circ}$ per cent dividing line, the latter were very probably simply being accurate.

\begin{tabular}{|c|c|c|c|}
\hline Used & Percentage & Reported & \\
\hline$\stackrel{|r|}{\phi}$ & $\begin{array}{l}|r| \\
79 \\
62\end{array}$ & $\begin{array}{l}\phi \\
2 I \\
38\end{array}$ & $\begin{array}{l}=100 \\
=100\end{array}$ \\
\hline
\end{tabular}

In the Norwich test, the criteria used were much more rigorous. In comparing the results obtained in the Self-Evaluation Test to forms actually used in Norwich, casual speech was used rather than formal speech, since CS more closely approximates everyday speech - to how informants normally pronounce words, which is what they were asked to report on. Moreover, informants were allowed no latitude in their self-evaluation. It was considered that the form informants used in everyday speech was the variant indicated by the appropriate $\mathrm{CS}$ index for that individual informant. For example, an (ng) index of between 050 and 100 was taken as indicating an (ng)-2 user rather than an (ng)-I user. In other words, the dividing line is $5^{\circ}$ per cent rather than Labov's more lenient 30 per cent. If, therefore, the characteristics of the Norwich sample were identical to those of the New York sample, we would expect a significantly higher degree of over-reporting from the Norwich informants.

The results, in fact, show the exact reverse of this, as can be seen from Table 4 .

This table gives the results of the Self-Evaluation Test for the variable (yu), which is the pronunciation of the vowel in items such as tune, music, queue, huge. In Norwich English items such as these have two possible pronunciations: (yu)-I has [j] as in RP-like [kju: kju:]; (yu)-2 omits [j] as in [ku: k3t], queue.

Table 4 provides a very striking contrast to the New York results shown in 
Table 3 in that only 16 per cent of (yu)-2 users, as compared to the equivalent figure of 62 per cent in New York, over-reported themselves as using the more statusful RP-like variant (yu)-I when they did not in fact do so. Even more significant, however, is the fact that as many as 40 per cent of (yu)-I users actually under-reported - and the under-reporting is in this case quite genuine.

A further breakdown of the scores given in Table 4 is also very revealing. Of the 16 per cent (yu)-2 users who over-reported, all were women. Of the (yu)-I users who under-reported, half were men and half women. Here we see, for the first time, the emergence of the hidden values that underlie the sex differentiation

TABLE 4. Self-Evaluation of $(y u)$

\begin{tabular}{|c|c|c|c|}
\hline Used & $\begin{array}{l}\text { (yu) Per } \\
\text { Repo }\end{array}$ & $\begin{array}{l}\text { centage } \\
\text { rted }\end{array}$ & \\
\hline $\begin{array}{l}\text { I } \\
2\end{array}$ & $\begin{array}{r}I \\
60 \\
16\end{array}$ & $\begin{array}{r}2 \\
40 \\
84\end{array}$ & $\begin{array}{l}=100 \\
=100\end{array}$ \\
\hline
\end{tabular}

TABLE 5. Percentage of informants over- and under-reporting $(y u)$

\begin{tabular}{lccc}
\hline \hline & Total & Male & Female \\
\hline Over-r & 13 & 0 & 29 \\
Under-r & 7 & 6 & 7 \\
Accurate & 80 & 94 & 64 \\
\hline
\end{tabular}

described earlier in this paper. If we take the sample as a whole, we have the percentages of speakers under- and over-reporting shown in Table 5. Male informants, it will be noted, are strikingly more accurate in their self-assessment than are female informants.

The hidden values, however, emerge much more clearly from a study of the other variables tested in this way, (er), ( $\overline{0})$ and $(\bar{a})$, illustrated in Tables 6,7 and 8 respectively. The variable (er) is the vowel in ear, here, idea, which in Norwich

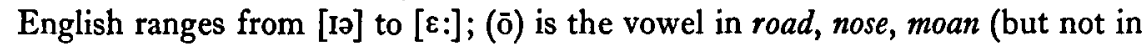
rowed, knows, mown, which are distinct) and ranges from [eu] through [u:] to $[\mathrm{v}]$; and $(\bar{a})$ is the vowel in the lexical set of gate, face, name, which ranges from [er] to [æi].

For each of these variables, it will be seen, there are more male speakers who claim to use a less prestigious variant than they actually do than there are who over-report, and for one of the variables $(\overline{0})$, the difference is very striking: 54 
per cent to 12 per cent. In two of the cases, moreover, there are more male speakers who ounder-report than there are who are accurate.

Although there are some notable differences between the four variables illustrated here, 4 it is clear that Norwich informants are much more prone to under-report than New York informants, and that - and this is central to our argument-male informants in Norwich are much more likely to under-report, female informants to over-report.

TABLE 6. Percentage of informants over-and under-reporting (er)

\begin{tabular}{llll}
\hline \hline & Total & Male & Female \\
\hline Over-r & 43 & 22 & 68 \\
Under-r & 33 & 50 & 14 \\
Accurate & 23 & 28 & 18 \\
\hline \hline
\end{tabular}

TABLE 7. Percentage of informants over-and under-reporting $(\bar{o})$

\begin{tabular}{llcc}
\hline \hline & Total & Male & Female \\
\hline Over-r & I8 & 12 & 25 \\
Under-r & 36 & 54 & 18 \\
Accurate & 45 & 34 & 57 \\
\hline \hline
\end{tabular}

TABLE 8. Percentage of informants over- and under-reporting $(\bar{a})$

\begin{tabular}{lllc}
\hline \hline & Total & Male & Female \\
\hline Over-r & 32 & 22 & 43 \\
Under-r & 15 & 28 & 0 \\
Accurate & 53 & 50 & 57 \\
\hline \hline
\end{tabular}

This, then, is the objective evidence which demonstrates that male speakers, at least in Norwich, are at a subconscious or perhaps simply private level very favourably disposed towards non-standard speech forms. This is so much the case that as many as 54 per cent of them, in one case, claim to use these forms or hear themselves as using them even when they do not do so. If it is true that informants 'perceive their own speech in terms of the norms at which they are

[4] These differences may be due to a skewing effect resulting from the necessity of using only a small number of individual lexical items to stand for each variable in the tests. (Informants' reports of their pronunciation of tune, for example, do not necessarily mean that they would pronounce or report Tuesday or tube in the same way.) 
aiming rather than the sound actually produced' then the norm at which a large number of Norwich males are aiming is non-standard WC speech. This favourable attitude is never overtly expressed, but the responses to these tests show that statements about 'bad speech' are for public consumption only. Privately and subconsciously, a large number of male speakers are more concerned with acquiring prestige of the covert sort and with signalling group solidarity than with obtaining social status, as this is more usually defined. By means of these figures, therefore, we have been able to demonstrate both that it is possible to obtain evidence of the 'covert prestige' associated with non-standard varieties, and that, for Norwich men, working-class speech is statusful and prestigious. The clear contrast with scores obtained by female informants, with as many as 68 per cent of the women over-reporting, in one case, underlines this point and indicates that women are much more favourably disposed towards MC standard forms. This in turn explains why the sex-differentiation pattern of Table 2 takes the form it does.

Why it should have been possible to obtain this sort of evidence of covert prestige from Norwich speakers but not from New York speakers it is difficult to say. This may be due to the fact that WC speakers in this country have not accepted $\mathrm{MC}$ values so readily or completely as WC speakers in America. If this is the case, it could be explained by 'the conspicuous lack of corporate or militant class consciousness [in America], which is one of the most important contrasts between American and European systems of stratification' (Mayer 1955:67) and by the related lack of 'embourgoisement' of the British WC (cf. Goldthorpe \& Lockwood 1963).

On the other hand, Tables 9 and ro show that this cannot be the whole story. These tables illustrate the amount of over- and under-reporting of (er) and (ō) respectively by male speakers as a whole, and then by MC as opposed to WC

TABLE 9. Percentage male informants overand under-reporting (er)

\begin{tabular}{llll}
\hline \hline & Total & MC & WC \\
\hline Over-r & 22 & 25 & 21 \\
Under-r & 50 & 50 & 50 \\
Accurate & 28 & 25 & 29 \\
\hline
\end{tabular}

male speakers. It can be seen that there is no significant difference in the behaviour of the two classes. The MC, it is true, shows a slightly greater tendency to over-report than the WC, but this is very small. The significant parameter controlling presence or absence of this 'covert prestige' is therefore sex rather than social class. Recognition of these hidden values is something that is common to a majority of Norwich males of whatever social class (and something that they 
do not share with WC female informants). Many MC males appear to share with WC males the characteristic that they have not so completely absorbed the dominant mainstream societal values as have their American counterparts.

Having established that covert prestige does in fact exist, and can be shown to exist, we are now in a position to move on to a discussion of one of the problems that arises from the Norwich data. It was shown in Table 2 that for the variable (ng) men had higher index scores than women. We also stated that the same

TABLEIO.Percentagemale informantsover-and under-reporting $(\bar{o})$

\begin{tabular}{lccc}
\hline \hline & Total & MC & WC \\
\hline Over-r & I2 & I5 & I I \\
Under-r & 54 & 54 & 54 \\
Accurate & 34 & 30 & 35 \\
\hline
\end{tabular}

TABLE I1. (o) Indices by class, style and sex

\begin{tabular}{clllll}
\hline & \multicolumn{5}{c}{ Style } \\
\cline { 2 - 6 } Class & Sex & WLS & RPS & FS & CS \\
\hline MMC & M & 000 & 000 & 001 & 003 \\
& F & 000 & 000 & 000 & 000 \\
LMC & M & 004 & 014 & 011 & 055 \\
& F & 000 & 002 & 001 & 008 \\
UWC & M & 011 & 019 & 044 & 060 \\
& F & 023 & 027 & 068 & 077 \\
MWC & M & 029 & 026 & 064 & 078 \\
& F & 025 & 045 & 071 & 066 \\
LWC & M & 014 & 050 & 080 & 069 \\
& F & 037 & 062 & 083 & 090 \\
& & & & & \\
\hline \hline
\end{tabular}

pattern occurred for the vast majority of other Norwich variables, and we have since been able to offer at least a partial explanation of why this pattern occurs. There is one Norwich variable, however, which does not conform to this pattern of sex differentiation. This is the variable (o), the pronunciation of the vowel in the lexical set of top, dog, box. There are two main variants in Norwich English: (o)-I, a rounded RP-like vowel [D]; and (o)-2, an unrounded vowel [a a]. Table II gives index scores for this variable by social class, contextual style and sex, and shows a pattern of differentiation markedly different from that shown for (ng) in Table 2.

As far as the two MC groups are concerned in all eight cases men again have scores that are higher than or equal to those of women. The striking fact to emerge 
from this table, however, is that for the three WC groups the normal pattern of sex differentiation is almost completely reversed. In ten cases out of twelve, women have higher scores than men. If it is true that for Norwich men WC non-standard speech forms have high covert prestige, then this would appear to be a counter-example which we have to explain. (This is the only Norwich variable for which a reversal of the pattern of sex differentiation was found.)

In order to be able to handle this problem we must first turn our attention to the examination of another variable, the variable (e). This is the pronunciation of the vowel in tell, bell, hell, for which there are three main variants: (e)-I $=[\varepsilon]$; $(\mathrm{e})-2=[3] ;(\mathrm{e})-3=[\Lambda]$. Table 12 shows index scores for this variable by class and style.

TABLE 12. (e) Indices by class and style

\begin{tabular}{lcccc}
\hline \multirow{2}{*}{ Class } & \multicolumn{4}{c}{ Style } \\
\cline { 2 - 5 } & WLS & RPS & FS & CS \\
\hline MMC & 003 & 000 & 001 & 002 \\
LMC & 007 & 012 & 023 & 042 \\
UWC & 027 & 039 & 089 & 127 \\
MWC & 030 & 044 & 091 & 087 \\
LWC & 009 & 026 & 077 & 077 \\
& & & & \\
\hline \hline
\end{tabular}

The figures given in this table illustrate quite clearly that the pattern of class differentiation for (e) differs rather strikingly from the normal pattern of differentiation illustrated for (ng) in Table $\mathrm{I}$. The difference lies in the fact that the bottom group, the LWC, consistently has scores that are lower (more nearly standard) than those of both the UWC and MWC. A regular pattern of differentiation could only be obtained by placing the LWC scores between those for the LMC and UWC. It should also be noted that the MWC has a lower score than the UWC in CS. In CS, in fact, the class differentiation pattern for the WC is completely the reverse of the normal pattern.

The answer to the problem of why this should be the case lies in some research that was carried out into linguistic change in Norwich English. It was noted several times in the course of this research that the LWC, as a relatively underprivileged group, appeared to be isolated from certain innovating tendencies. Since we have found in the case of (e) that the LWC is differentiated from the UWC and the MWC in an unusual way, we can guess that high scores for this variable (that is, a large amount of non-standard centralization) represent an innovation in Norwich English: the variable (e) is involved in linguistic change, in that centralization of this vowel is increasing. We can further hypothesize that in the vanguard of this linguistic change, which would appear to be leading Norwich English in a direction away from the RP standard, are the upper 
members of the WC. The LWC and LMC are also participating in this change, but at a lower level, and the MMC are not participating at all, or very little.

This hypothesis is in fact confirmed by the pattern of age differentiation illustrated in Table 13. This illustrates that younger people in Norwich, those aged under 30 and in particular those aged under 20 , have much higher (e) scores than the rest of the population. This is particularly true of the crucial CS scores. Only the youngest two age groups achieve scores of too or over. This large amount of age differentiation confirms that a linguistic change is in fact taking place in Norwich.

TABLE 13. (e) Indices by age and style

\begin{tabular}{lcccc}
\hline & \multicolumn{4}{c}{ Style } \\
\cline { 2 - 5 } Age & WLS & RPS & FS & CS \\
\hline $10-19$ & 059 & 070 & 139 & 173 \\
$20-29$ & 021 & 034 & 071 & 100 \\
$30-39$ & 025 & 031 & 059 & 067 \\
$40-49$ & 015 & 026 & 055 & 088 \\
$50-59$ & 006 & 013 & 035 & 046 \\
$60-69$ & 005 & 018 & 055 & 058 \\
$70+$ & 005 & 031 & 050 & 081 \\
& & & & \\
\hline \hline
\end{tabular}

It is therefore possible to suggest that linguistic changes in a direction away from the standard norm are led in the community by members of the UWC and MWC. In particular, because of the covert prestige non-standard forms have for them, we would expect changes of this type to be spear-headed by MWC and UWC men. (Correspondingly, standard forms will tend to be introduced by MC women.) This point is confirmed in the case of (e), since the highest (e) index score of all was obtained in CS by male MWC ro-rg-year-olds, who had a mean index of 200 , i.e. they all consistently used (e)-3 in CS.

It is interesting to relate this change in a non-standard direction to the concept of covert prestige. We have already seen that for Norwich men this kind of prestige is associated with non-standard forms. But it also appears to be the case that very high covert prestige is associated with WC speech forms by the young of both sexes. Tables 14 and 15 illustrate this point. They compare the figures obtained in the Self-Evaluation Test for (er) and (ō) respectively by male WC speakers as a whole with those obtained by male WC speakers aged under 30 . In the case of female speakers, because of the size of the sample at this point, it was not possible to remove class bias from the data, and the figures for female speakers also shown in Tables $\mathrm{I}_{4}$ and $\mathrm{I}_{5}$ simply compare scores obtained by female speakers as a whole with those of the female under-30 group. 
In the case of (er) it is clear that younger informants are rather more accurate in their self-evaluation than are older informants. With the female informants this is particularly striking: 40 per cent accuracy as compared to only $\mathrm{I} 8$ per cent accuracy from the female sample as a whole. In the case of $(\bar{o})$, the differences are rather more striking. The younger informants are slightly less accurate than the sample as a whole, but this is due to a greater tendency - and in the case of the female informants a much greater tendency - to under-report. It is therefore not only male speakers who attach covert prestige to WC speech forms, but also the younger female informants. Whether this is a feature which is repeated in every

TABLE 14. Percentage of informants over-and underreporting (er) by age

\begin{tabular}{lccccc}
\hline \hline & \multicolumn{2}{c}{ Male } & & \multicolumn{2}{c}{ Female } \\
\cline { 2 - 3 } \cline { 5 - 6 } Percentage & Total & WC & & Total \\
WC & ro-29 & & Female & 10-29 \\
\hline Over-r & 21 & 8 & & 68 & 40 \\
Under- & 50 & 58 & & 14 & 20 \\
Accurate & 29 & 33 & & 18 & 40 \\
\hline \hline
\end{tabular}

TABLE 15. Percentage of informants over- and underreporting $(\bar{o})$ by age

\begin{tabular}{lccccc}
\hline \hline & \multicolumn{2}{c}{ Male } & & \multicolumn{2}{c}{ Female } \\
\cline { 2 - 3 } \cline { 5 - 6 } Percentage & Total & WC & WC & & Total \\
10-29 & & Female & 10-29 \\
\hline Over-r & 8 & 8 & & 25 & 0 \\
Under-r & 50 & 58 & & 18 & 50 \\
Accurate & 42 & 33 & & 57 & 50 \\
\hline
\end{tabular}

generation of female speakers, or whether it reflects a genuine and recent change in ideology it is not possible at this stage to say. What is clear, however, is that the linguistic change associated with (e) is being caused, at least in part, by the covert prestige which the WC form $[\Lambda]$ has for certain Norwich speakers. Group-identification of a kind considered desirable by these speakers is signalled by the usage of the non-standard form, and this leads, to its increase and exaggeration. Covert prestige, therefore, leads not only to the differentiation of the linguistic behaviour of the sexes, but also to the exaggeration of certain nonstandard features, particularly by UWC and MWC men and by the young, which in turn leads to linguistic change.

If we now return once again to the unusual pattern associated with (o) illus- 
trated in Table I I, we might again hypothesize that the deviant configuration of scores obtained for this variable is due, as in the case of (e), to a linguistic change in progress. However, this does not at first sight appear possible, since, if the RP form [D] were being introduced into Norwich English, we would clearly expect this process to be spear-headed by MC women. The answer would appear to lie in the fact that [D] is not only an RP form. It is also the form that occurs in the speech of the Home Counties and, perhaps more importantly, in Suffolk. Field records made in the 1930s by Lowman, 5 some of which are published in Kurath $\&$ McDavid (r96r), give the pronunciation of the vowel in items such as bog as $[\mathrm{D}]$ in Suffolk and this pronunciation is also recorded for the Suffolk localities in Orton \& Tilling (I969).

It would therefore seem to be the case that the unusual pattern of sex differentiation of $(o)$ is due to the following processes. The form [D] in items such as top,

TABLE I6. (o) Indices by age and style

\begin{tabular}{lllll}
\hline & \multicolumn{4}{c}{ Style } \\
\cline { 2 - 5 } Age & WLS & RPS & FS & CS \\
\hline $10-29$ & 017 & 017 & 045 & 055 \\
$30-49$ & 020 & 030 & 039 & 063 \\
$50-69$ & 021 & 037 & 058 & 067 \\
$70+$ & 043 & 043 & 091 & 093 \\
\hline
\end{tabular}

$d o g$ is being introduced as a linguistic innovation into Norwich English. This is demonstrated by the scores shown for different age groups in Table I6. The introduction of this innovation, moreover, is taking place in two ways. First, [D] is being introduced into Norwich English from RP by MC women, who are not only orientated towards RP, as the Self-Evaluation Tests show, but also have access to RP forms, in a way that WC women do not, because of their social class position. Secondly, this form is being introduced, as a result of geographical diffusion processes, from the non-standard WC speech forms of the Home Counties and particularly Suffolk by WC men, who not only are favourably disposed towards non-standard forms just as MC men are, but also, because of their social class position, have access to these forms as a result of occupational and other forms of social contact with speakers of [p]-type accents. The variable (o) therefore represents a relatively rare example of two different types of linguistic change (change 'from below' and 'from above' in the terms of Labov 1966: 328 ) both leading in the same direction, with the result that it is now only WC women who, to any great extent, preserve the unrounded vowel.

[5] I am very grateful to R. I. McDavid who went to a great deal of trouble to enable me to consult these records. 
We have therefore been able to argue that 'covert prestige' can be associated with certain linguistic forms, and that it is possible in some cases to provide evidence to show that this is in fact the case. This covert prestige reflects the value system of our society and of the different sub-cultures within this society, and takes the following form: for male speakers, and for female speakers under $3^{\circ}$, non-standard WC speech forms are highly valued, although these values are not usually overtly expressed. These covert values lead to sex-differentiation of linguistic variables of a particular type that appears to be common to at least some varieties of urban British and American English. Covert prestige also appears to lead to linguistic changes 'from below', with the result, for example, that in Norwich English non-standard variants of (e) are currently on the increase. A study of the actual form the sex differentiation of a particular linguistic variable takes, moreover, can also usefully be employed in an examination of whether or not the variable is involved in linguistic change.

One important conclusion of a practical nature that we can draw from this data is that, if we wish to teach standard English to younger speakers of nonstandard English (and the necessity for this has been disputed - see O'Neil I968; Newmeyer \& Edmonds 197I), we should be very careful to take values of the covert prestige type into consideration. Levine \& Crockett (I966) have demonstrated that in one American locality 'the community's march toward the national norm' is spear-headed in particular by middle-aged MC women (and by the young). In Norwich, at least, there appears to be a considerable number of young WC men marching resolutely in the other direction.

\section{REFERENCES}

Crystal, D. (1971). Prosodic and paralinguistic correlates of social categories. In E. Ardener (ed.), Social anthropology and language. London: Tavistock.

Fasold, R. W. (I968). A sociolinguistic study of the pronunciation of three vowels in Detroit speech. Unpublished mimeo: Center for Applied Linguistics.

Fischer, J. L. (1958). Social influences on the choice of a linguistic variant. Word 14. 47-56.

Goldthorpe, J. \& Lockwood, D. (1963). Affluence and the British class structure. Sociological Review Ir. 133-63.

Haas, M. (1944). Men's and women's speech in Koasati. Lg. 20. 142-9.

Hertzler, J. (1954). $A$ sociology of language. New York: Random House.

Jespersen, O. (1922). Language: its nature, development and origin. London: Allen and Unwin.

Kurath, H. \& McDavid, R. I. (196r). The pronunciation of English in the Atlantic states. Ann Arbor: University of Michigan Press.

Labov, W. (1966). The social stratification of English in New York City. Washington, D.C.: Center for Applied Linguistics.

- ( $1966 \mathrm{~b}$ ). Hypercorrection by the lower middle class as a factor in linguistic change. In W. Bright (ed.), Sociolinguistics. The Hague: Mouton.

Levine, L. \& Crockett, H. J. (Ig66). Speech variation in a Piedmont community: postvocalic $\mathrm{r}$. In S. Lieberson (ed.), Explorations in sociolinguistics. The Hague: Mouton.

Martin, F. M. (1954). Some subjective aspects of social stratification. In D. V. Glass (ed.), Social mobility in Britain. London: Routledge and Kegan Paul. 


\section{SEX, COVERT PRESTIGE AND LINGUISTIC CHANGE}

Mayer, K. B. (1955). Class and society. New York: Random House.

O'Neil, W. (1968). Paul Roberts' rules of order: the misuse of linguistics in the classroom. The Urban Review 2. 12-17.

Newmeyer, F. J. \& Edmonds, J. (1971). The linguist in American society. Papers from the the $7_{\text {th }}$ regional meeting of the Chicago linguistic society. Chicago: Chicago Linguistic Society.

Orton, H. \& Tilling, P. M. (1969). Survey of English dialects: volume III East Midlands and East Anglia. Leeds: Arnold.

Sapir, E. (1929). Male and female forms of speech in Yana. Reprinted in D. Mandelbaum (ed.) (1949), Selected writings of Edward Sapir in language, culture and personality. Berkeley and Los Angeles: University of California Press.

Shuy, R. W. (1969). Sociolinguistic research at the Center for Applied Linguistics: the correlation of language and sex. Giornata internazionali di sociolinguistica. Rome: Palazzo Baldassini.

Shuy, R. W., Wolfram, W. A. \& Riley, W. K. (1967). Linguistic correlates of social stratification in Detroit speech. Cooperative Research Project 6-1347. East Lancing: U.S. Office of Education.

Trudgill, P. J. (197I). The social differentiation of English in Norwich. Edinburgh University: Unpublished Ph.D. Thesis.

Wolfram, W. A. (1969). A sociolinguistic description of Detroit negro speech. Washington, D.C.: Center for Applied Linguistics. 